\title{
Research on Flipped Classroom and Micro Classroom in English Teaching
}

\author{
Qingyuan Luo \\ Chengdu Neusoft University, Chengdu, Sichuan, 611844 China
}

\begin{abstract}
The teaching mode of flipped classroom and micro class has gradually entered the daily teaching of College English classes. The new teaching concept and teaching mode not only promote the reform of the teaching mode in College English course, but also improve the teaching quality of College English course. This paper makes a rational distribution of teachers' tasks and students' tasks through the integration of "network model" and "classroom model", and designs the interactive turnover mode in College English teaching practice, which can promote the application of Information Science Technology in College English teaching.
\end{abstract}

Keywords: Flipping Classroom; Micro lecture; College English teaching; Interactive mode.

\section{Introduction}

With the development of socialist market economy and continuous integration of the international market, the opportunities for domestic enterprises in international market are increasing. At the same time, the requirements of domestic enterprises for college graduates' English ability are also increasing. As the main channel for providing high-quality innovative talents to the society, the teaching quality of College English courses directly affects the English proficiency level of the college graduates and their work in the future.

Despite the increasingly vigorous development of globalization, the demand for college graduates' English comprehensive ability has been further improved, and the degree of concern for College English course quality has been greatly improved. However, it has been developing and innovating in College English teaching and teaching. There are still some defects and deficiencies in the following aspects: First of all, at present, the teaching mode of College English Curriculum in Universities in China still has some shortcomings, such as relatively backward teaching ideas and relatively simple teaching methods. In the course of actual teaching, teachers tend to mainly cultivate students' ability to test, and to a great extent ignore the cultivation of students' comprehensive practical application ability, which leads to the students' English ability is often difficult to meet the specific needs of practical application. Second, College English is as one of the basic courses in Colleges and universities, its course teaching form is often a large class teaching, which leads to teachers in the course of classroom teaching, teachers often only interact with a few students in the classroom, and the classroom participation is relatively poor. It cannot satisfy the actual needs of students with different learning abilities in classroom, and at the same time, reduce the enthusiasm of students to attend lectures. This leads to classroom teaching hard to play its due educational effect.

\section{The main characteristics and advantages of flipped classroom and micro class teaching}

\subsection{The main teaching features of flipped and micro class teaching}

Flipped Classroom refers to the scientific and standardized measures and means to adjust the classroom teaching mode, teaching content and teaching time, so as to achieve the purpose of highlighting the main body status of the students, active classroom teaching atmosphere and improving the quality of classroom teaching. In the new model of the flipping class, the initiative of classroom learning is delivered to the students' hands to the greatest extent, and the teacher can also get more time and energy to take care of and help each student in the class. Therefore, it can effectively improve the quality of classroom teaching, and promote students to acquire more profound understanding and mastery related knowledge through classroom learning.

Micro lecture refers to the aid of modern information technology means, through the concrete form of fragmentation teaching video, it is an innovative teaching 
means to highlight the focus of their own teaching. The teaching of micro class has the advantages of distinct theme, specific content, relatively short teaching time and convenient application of resources, so it is helpful for students to obtain the best learning effect in the limited time of study.

Through the combination of the flipping class and the micro class teaching model, it not only helps to highlight the students' subjective status in the classroom teaching, but also promotes the classroom teaching atmosphere. At the same time, it can also effectively increase the communication and interaction between students and students, and help students to learn and master the course content better. Improve the quality of teaching.

\subsection{Advantages of flipped classroom and micro lesson teaching}

First, the innovative application of the flipped and micro class teaching in College English courses can effectively promote the development of students' personality, improve the students' practical application ability, thinking ability and critical thinking ability. Compared with the traditional instilled classroom teaching mode, the innovative application of the flipped class and the micro class teaching will not only help to improve the students' self-learning ability and the anxiety of the class, but also make the development of the course content easier through the application of the Internet tools. This is almost unrestricted around the teaching theme in many aspects of thinking, therefore, the teaching method can further provide a good basic guarantee for the students' practical application ability, comprehensive thinking ability and critical thinking.

Secondly, the innovative application of the flipped class and the micro class teaching in the College English course can effectively activate the classroom teaching atmosphere, increase the communication between the students and students, and help the students to remember and understand the teaching content better, and further enhance their own comprehensive practice ability and application knowledge ability. In addition, in the classroom teaching, the continuous increase communication between teachers and students can help students to better solve the difficulties encountered in their own learning process, and fundamentally improve the quality of students' learning.

Finally, the innovative application of the flipped and micro class teaching in College English courses can also effectively promote the comprehensive improvement of students' Comprehensive English ability and practical application ability, thus laying a solid foundation for better meeting the specific needs of students in the future study.

\subsection{Feasibility analysis of the application of flipped classroom and micro class in college English teaching}

First, from the point of view of teachers, the practical application of the flipped and micro class teaching in College English course makes the teachers better adjust and control the teaching content and teaching link in the process of daily teaching, further active the teaching atmosphere of the class and improve the enthusiasm and initiative in students' self-study. On the one hand, College English courses are relatively innovative and flexible in their own courses, so in the actual teaching process, teachers can more effectively introduce the advantages of the flipped and micro class teaching into the teaching of College English courses, and better interact with the students in classroom teaching. On the other hand, in the practical application process of the flipped and micro class teaching, teachers can also combine their own learning experience to develop a set of more targeted courseware for the students to further enhance the quality of teaching.

Secondly, from the point of view of the students, the practical application of the flipped class and the micro class teaching in the College English course makes the students have the autonomy of autonomous learning and the initiative of the classroom learning in the process of daily learning, so as to further reduce the resistance and reverse psychology of the students. It has laid a good foundation for enhancing students' initiative in autonomous learning. On the one hand, because the college students have a certain autonomous learning ability, the teaching mode of overturning the classroom and micro class can effectively promote the students to think independently of the curriculum content in the course of classroom learning; On the other hand, because of the convenience of the teaching courseware and the content of the video, the students will be able to review and consolidate the content they have learned, so that the students' need for self-study can be greatly met, and it further improve the quality of College English teaching.

\section{Research on the flipped classroom and micro class in college English teaching}

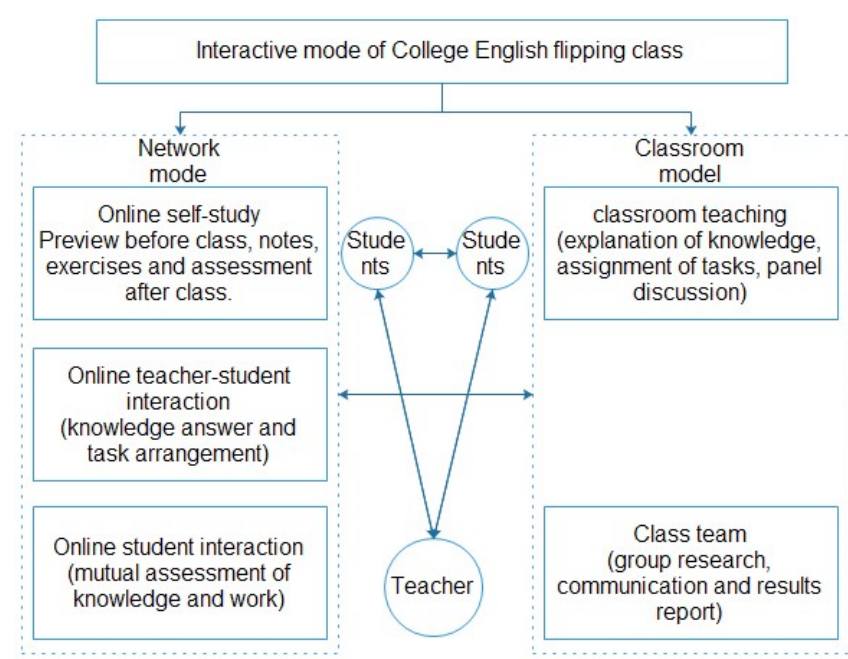

Figure 1. The interactive model of college English flipping classroom.

The interactive mode of College English flipped classroom is shown in Figure 1. The detailed exposition of network mode and classroom model in the College English 
reversal classroom can be found that the teaching forms of the College English turn over class have both personal and team cooperative learning, which has both textbook and extracurricular development.

\subsection{Online autonomous Learning}

Students are the main body of web-based autonomous learning. The main contents of the study include preview, text explanation, after class exercises and stage assessment of College English textbooks.

Pre class preparation is mainly carried out by students based on network micro video. These micro videos are carefully recorded by teachers in advance and uploaded to the learning platform for students to use. Each unit has a corresponding micro video to introduce the learning focus and learning goal of this unit, so that students have a macro understanding of the learning content of this unit.

\subsection{Network interaction between teachers and students}

The main body of network teacher-student interaction is teachers and students. The content of interaction mainly includes knowledge answering questions and task arrangement.

Knowledge answering mainly refers to the teachers answers to the questions that students appear in text learning and after-school exercises. The specific processes include students' finding problems, students' online submission, teachers' online answering questions and students' online feedback questions. Another link of network teacher-student interaction is task layout. Teachers can assign students online assignments on the topic of this unit. After the teacher assigns the task through the system, the student will receive a reminder on the client side, and then check the details of the task (including content, time and requirements). After the student completes the task online, the teacher begins to read the student's homework. After a class's homework correction is completed, the teacher can directly export the class performance analysis table, and have an intuitive cognition of the whole class's performance. Teachers can give feedback on homework and performance analysis to students, so that students can have a comprehensive understanding of their writing level.

\subsection{Network interaction between students}

The main body of the interaction between the students of the network is the student group. The content of interaction mainly includes mutual knowledge check and homework mutual evaluation.

Mutual knowledge check is achieved in the form of a team. First, the students in a class are divided into groups. The members of the group can ask questions online around the text knowledge points. The students with many questions or more answers will get the corresponding rewards points. Secondly, teams and groups can test each other's knowledge points and give full play to their sense of teamwork

\subsection{Classroom teaching model}

The main body of classroom teaching is teachers and students. Classroom teaching mainly includes knowledge explanation, task arrangement, group discussion and group presentation.

Classroom teaching inherits the advantages of traditional classroom teaching and carries out teaching activities in the classroom environment. The first teaching activity of this link is the explanation of knowledge. Knowledge explanation refers to teachers' knowledge points in teaching texts, including words, sentences, textual structures and semantics. The purpose of this teaching link is to encourage teachers and students to exchange knowledge and ask questions in a face-to-face way, so as to promote teaching and learning. The premise of the task arrangement is that the students have acquired the basic knowledge. The assignment content is mainly centered on a topic. After the task is assigned, the students will discuss in the form of a group. Group discussion can adopt a variety of ways, in short, let the group members speak freely, inspire and encourage each other, and form a consistent discussion result. Group presentation is a follow-up part of group discussion, aiming to systematically report the conclusions of the panel discussion. This link can be carried out step by step, and the members of the group should have a clear division of labor. Each member is responsible for the specific work of a specific part. This link can fully exercise the cooperation ability of team members and fully cultivate students' team consciousness.

\section{Conclusions}

The interactive model of College English flipping class combines "network model" and "classroom model", and through the transformation of teachers and students' identity, the three interactive goals of College English innovative teaching are realized, namely "network and classroom interaction", "interaction between teachers and students" and "interaction between students and students". This not only promotes the construction of College English flipped classroom, but also promotes the integration of information technology in College English teaching. The model aims to promote the dual transformation of teachers and students. As far as the teacher is concerned, it changes the dominant position in the traditional college English classroom teaching, and participates in the teaching activities as well as the students, giving students more opportunities for self-study. As far as students are concerned, students are no longer in the passive position to accept knowledge. Instead, they begin to learn actively, find problems, ask questions and solve problems. The dual transformation of teachers and students makes college English teaching achieve a real "flip".

\section{Acknowledgement}

Subject: Project of Education Department of Sichuan Province in 2018 
An empirical study on the effectiveness of $\mathrm{CDIO}+$ flipped classroom Teaching Model on the course of Business Comprehensive English 18SB0029.

\section{References}

1. Wang Ruixing, Liang Xianli, Liu Junying. Application of "flipped classroom" teaching mode in Higher Mathematics Teaching [J]. Education Teaching Forum, 2017, (18): 61-63.
2. Zhou Ping. The reversal classroom based on modern educational technology and its theoretical foundation [J]. Technology Enhanced Foreign Language Education, 2015, (162): 72-77.

3. Wang ShouRen. Adhere to the scientific concept of College English Teaching Reform [J]. Foreign Language World, 2013, (6): 9-13, 22.

4. Dong Zhanhai, Xing Lei. Quasi experimental study on the turnover of college physics classes in Engineering [J]. Research in Higher Education of Engineering, 2018, (1): 136-138, 145. 